\title{
Classification and analysis of the non stoichiometry features in the layered lead and thallium cuprates
}

\author{
Maryvonne Hervieu, Claude Michel and Bernard Raveau
}

Laboratoire de Cristallographie et Sciences des Matériaux ISMRa, Campus 2, Boulevard du Maréchal Juin, 14050 Caen Cedex, France

(Received October 01, 1990; accepted January 15, 1991)

\begin{abstract}
Résumé. - Le nombre et la variété des causes de non-stoéchiométrie existant dans les supraconducteurs à haute température critique sont directement engendrés par les modes de construction de ces structures, c'est à dire l'intercroissance des couches de type $\mathrm{NaCl}$ et de type perovskite déficitaire en oxygène. La coexistence de plusieurs cations (jusqu'à 6) dans la matrice, les possibilités de valence mixte pour certains cations ( $\mathrm{Cu}-\mathrm{Bi}-\mathrm{Tl}-\mathrm{Pb}-\mathrm{Pr}$ ) et la possibilité d'occupation des sites cristallographiques par plusieurs cations simultanément, sont, sans aucun doute, des facteurs susceptibles de favoriser leur existence. La reconnaissance de ces nombreux phénomènes peut apparaître comme un "hobby" de microscopiste. En fait, l'importance des caractéristiques microstructurales a largement été prouvée par les études sur les supraconducteurs: l'existence de défauts étendus peut être un obstacle à une interprétation fine des propriétés physiques, l'examen des mécanismes structuraux peut ouvrir la voie de la découverte de nouvelles phases et peut être d'une aide essentielle pour l'optimisation des matériaux. Cet article traite de la classification des phénomènes qui sont observés et de l'analyse des mécanismes structuraux intervenant dans les cuprates au plomb et au thalium ; à cause de leur comportement particulier, les cuprates au bismuth sont seulement abordés à titre de comparaison.
\end{abstract}

\begin{abstract}
The numerous and varied non stoichiometry features occuring in the high $T_{\mathrm{c}}$ superconductors are directly generated by the own nature of the building principles of these structures i.e. the intergrowth of rock salt-type layers and oxygen deficient perovskite slabs. The coexistence of several cations (sometimes up to six) in the matrix, the possibilities of mixed valencies for some of these cations $(\mathrm{Cu}-\mathrm{Bi}-\mathrm{Tl}-\mathrm{Pb}-\mathrm{Pr})$ and the possible occupancy of the crystallographic sites by several cations simultaneously are undoubtly factors susceptible to favor their appearance. Is the acquaintance of these numerous phenomena only a microscopist hobby? The importance of the microstructural characterization has been widely proved in different stages of the superconductor studies: the existence of extended defects can indeed hinder an accurate interpretation of the physical properties, the survey of the structural mechanisms can open the road to the discovery of new phases and can be an essential help in the optimization of these materials. This paper deals with the classification of the phenomena which can be observed and the analysis of the structural mechanisms which are involved in the lead and thallium cuprates; owing to their particular behavior, bismuth cuprates will be only considered as a comparison.
\end{abstract}




\section{Structural considerations.}

Considering the general formulation $\left(\mathrm{ACuO}_{3-x}\right)_{m}(\mathrm{AO})_{n}$ of the high $T_{\mathrm{c}}$ superconductors [1], the $m$ and $n$ values express the number of perovskite (P) and rock salt-type (R.S.) layers respectively. The cations of the matrix are localized in four types of crystallographic sites distributed among different layers; the nature of these layers is indeed directly related to the rock salt and perovskite structures and their numbers directly correlated to the $n$ and $m$ values. In that way, and "ideal" member of the parent structures is built up from:

$-m\left[\mathrm{CuO}_{2}\right]_{\infty}$ "copper layers" $-m^{-1}[\mathrm{~A}]_{\infty}$ oxygen free layers, intercalated between the copper layers within the perovskite slab. The A ions exhibits the eight-fold coordination of the "fluorite"type cage.

$-2[\mathrm{AO}]_{\infty}$ "junction" layers which ensure the junction between the perovskite and the rock salt slabs.

$-[n-1][\mathrm{AO}]_{\infty}$ rock salt layers intercalated between the two "junction" layers.

The $\mathrm{TlBa}_{2} \mathrm{CaCu}_{2} \mathrm{O}_{7}$ structure illustrates the layers stacking in figure 1 . This $[2,2]$ member, referring to the $m$ and $n$ values respectively, is also called " 1212 " refering to $[n-1,2, m-1, m]$, numbers of the different types of layers: R. S. intercalated, junction, P. intercalated and copper layers respectively.

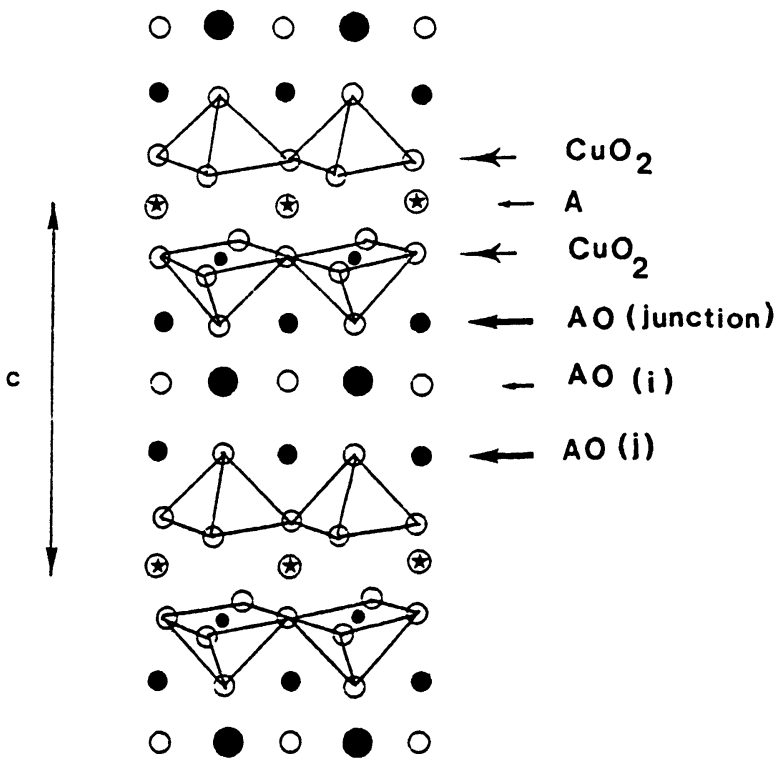

Fig. 1. - $\mathrm{TlBa}_{2} \mathrm{CaCu}_{2} \mathrm{O}_{7}$, idealized structure of a $[2,2]$ member. Details of the different layers.

For the thallium compounds, $n$ varies from 2 to 3 and $m$ from 1 to 4 , in the $\mathrm{TlBaCaCuO}$ system. Pure oxides can be synthesized by complete or partial cation substitution: $\mathrm{Tl} / \mathrm{Bi}, \mathrm{Tl} / \mathrm{Pb}, \mathrm{Ba} / \mathrm{Sr}$, $\mathrm{Ba} / \mathrm{Tl}, \mathrm{Sr} / \mathrm{Ln}, \mathrm{Ca} / \mathrm{Sr}$ and $\mathrm{Sr} / \mathrm{Ln}$. (Tab. I).

For the lead compounds, a specific character is observed: in the $[\mathrm{AO}]_{\infty}$ layers, lead cation is always associated to a second $\mathrm{A}$ cation $(\mathrm{Pb} / \mathrm{Tl} ; \mathrm{Pb} / \mathrm{Bi} ; \mathrm{Pb} / \mathrm{Sr} ; \mathrm{Pb} / \mathrm{Ca} ; \mathrm{Pb} / \mathrm{Ba})$ in a statistical or an ordered way, with $\mathrm{Pb} / \mathrm{A} \leq 1$; moreover lead can exibit a mixed valence $\mathrm{Pb}^{\mathrm{II}}-\mathrm{Pb}^{\mathrm{IV}}$. We will consider, in this paper, only the lead cuprates where $\mathrm{Pb} / \mathrm{A}=1$. (Tab. I). 
Table I. - a) Parent structures. b) Related structures.

a)

\begin{tabular}{|c|c|c|c|}
\hline$m / n$ & 1 & 2 & 3 \\
\hline 1 & & $\begin{array}{c}\mathrm{Tl}_{0.5} \mathrm{~Pb}_{0.5} \mathrm{Sr}_{2} \mathrm{CuO}_{5-\delta} \\
\mathrm{TlSr}_{2} \mathrm{CuO}_{5} \\
\mathrm{Tl}_{1-x} \mathrm{Pr}_{x+y} \mathrm{Sr}_{2-y} \mathrm{CuO}_{5-\delta} \\
\mathrm{TlBa}_{1+x} \mathrm{La}_{1-x} \mathrm{CuO}_{5} \quad[26]\end{array}$ & $\mathrm{Tl}_{2} \mathrm{Ba}_{2} \mathrm{CaCuO}_{6} \quad[15]$ \\
\hline 2 & & 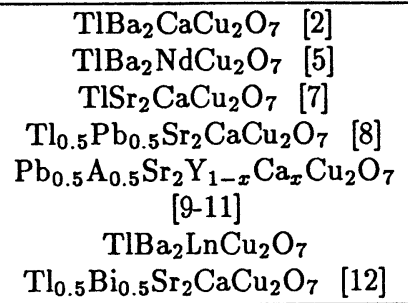 & $\begin{array}{c}\mathrm{Tl}_{2} \mathrm{Ba}_{2} \mathrm{CaCu}_{2} \mathrm{O}_{8} \quad[16] \\
\mathrm{BiPbSrYCu}_{2} \mathrm{O}_{8} \quad[17] \\
\mathrm{Tl}_{2-x} \mathrm{Ba}_{1-x} \mathrm{Tl}_{x} \mathrm{LnCu}_{2} \mathrm{O}_{8} \quad[18]\end{array}$ \\
\hline 3 & $\mathrm{PbBaSrYCu}_{3} \mathrm{O}_{8}[3]$ & $\begin{array}{c}\mathrm{TlBa}_{2} \mathrm{Ca}_{2} \mathrm{Cu}_{3} \mathrm{O}_{9} \\
\mathrm{Tl}_{0.5} \mathrm{~Pb}_{0.5} \mathrm{Sr}_{2} \mathrm{Ca}_{2} \mathrm{Cu}_{3} \mathrm{O}_{9}\end{array}$ & $\mathrm{Tl}_{2} \mathrm{Ba}_{2} \mathrm{Ca}_{2} \mathrm{Cu}_{3} \mathrm{O}_{10} \quad[16-19]$ \\
\hline 4 & & $\mathrm{TlBa}_{2} \mathrm{Ca}_{3} \mathrm{Cu}_{4} \mathrm{O}_{11} \quad[14]$ & $\mathrm{Tl}_{2} \mathrm{Ba}_{2} \mathrm{Ca}_{3} \mathrm{Cu}_{4} \mathrm{O}_{12} \quad[20]$ \\
\hline
\end{tabular}

b)

\begin{tabular}{|l|}
\hline $\mathrm{Pb}_{2} \mathrm{Sr}_{2} \mathrm{Y}_{1-x} \mathrm{Ca}_{x} \mathrm{Cu}_{3} \mathrm{O}_{8+\delta} \quad[21]$ \\
$\mathrm{Pb}_{2-x} \mathrm{Bi}_{x} \mathrm{Sr}_{2} \mathrm{Y}_{1-y} \mathrm{Ca}_{y} \mathrm{Cu}_{3} \mathrm{O}_{8+\delta} \quad[22]$ \\
$\mathrm{Pb}_{2} \mathrm{Sr}_{2-x} \mathrm{La}_{x} \mathrm{Cu}_{2} \mathrm{O}_{6+\delta} \quad[23]$ \\
\hline $\mathrm{Tl}_{1+x} \mathrm{~A}_{2-y} \mathrm{Ln}_{2} \mathrm{Cu}_{2} \mathrm{O}_{9}[24]$ \\
$\mathrm{Pb}_{2} \mathrm{Sr}_{2} \mathrm{Ln}_{2} \mathrm{Cu}_{3} \mathrm{O}_{10} \quad[25]$ \\
$\mathrm{Ln}_{2-x} \mathrm{Ba}_{2-y} \mathrm{Ce}_{x} \mathrm{Ln}_{y} \mathrm{Cu}_{3} \mathrm{O}_{10} \quad[51]$ \\
$\mathrm{Bi}_{2} \mathrm{Sr}_{2} \mathrm{Ln}_{2-x} \mathrm{Ce}_{x} \mathrm{Cu}_{2} \mathrm{O}_{10} \quad[52]$ \\
\hline
\end{tabular}

\section{The defects.}

One way to classify and analyze the numerous defects occuring in the superconducting cuprates is to take into consideration the mechanisms implied in these features. In the thallium and lead oxides, the main features are related to the layers stacking and intercalation, order-disorder phenomena, interruption and interconnection of the different layers and domains formation.

2.1 LAYER STACKING. - Variation in the layers stacking with regard to the ideal sequences are indeed the most probable event in intergrowth phases. We will distinguish two types of variations: firstly the existence of defective slabs, characterized by $m^{\prime}$ or/ and $n^{\prime}$ values different from the $m$ and $n$ values of the nominal composition but built up from similar layers and second, the existence of defective slabs built up from the intercalation of layers of different nature [20, 27-35].

2.1.1 Intergrowth defects. - The appearance of $m^{\prime}$ defective layers in a $[m, n]$ member is a very classical defect of the intergrowth phases built up from perovskite layers:

"In a general way, the number of defects increases with $m$ and the $\Delta m=\left|m-m^{\prime}\right|$ value is close to one for low $m$ values and increases with $m$." 
Large perovskite slabs, $m^{\prime} \geq 7$, have been observed in thallium compounds [20] where regular $m=4$ members exist as pure phases. In the lead oxides, members with $m>3$ have not been, up to now, isolated and moreover, the existence of defective member $m^{\prime}>3$ has never been reported. The absence of large defective perovskite slabs in the lead oxides can indeed be ascribed to the low values of the different $m$ members but a second factor can be taken into consideration, related to the constant presence of a trivalent cation in the $[\mathrm{A}]_{\infty}$ layer. Such a phenomenon is observed too in the thallium oxides when $\mathrm{Ln}^{3+}$ substitutes $\mathrm{Ca}^{2+}$.

"When $\left[\mathrm{A}^{\mathrm{II}}\right]_{\infty}$ layers $(A=C a, S r)$ are replaced by $\left[\mathrm{A}^{\mathrm{III}}\right]_{\infty}$ layers $(A=Y, N d, P r .$.$) , only$ double perovskite slabs are observed, as well as pure member as defective member".

In that way, in $\mathrm{TlBa}_{2} \mathrm{NdCu}_{2} \mathrm{O}_{7}(6), m^{\prime}=3$ slabs have never been observed; defective members have been indeed observed but with $m^{\prime}=1$ which does not involve the existence of intercalated [A $]_{\infty}$ layers (Fig. 2a). This feature could be related to the shape of the $\mathrm{AO}_{8}$ cage where these cations are located. The pseudo-cubic shape of the $\mathrm{Y}$ and $\mathrm{Nd}$ cages implies a displacement of the copper atoms to avoid short $\mathrm{Cu}-\mathrm{Cu}$ distances, contrary to the elongated shape of the $\mathrm{CaO}_{8}$ cages (Fig. 2b). In the $m=2$ members, built up from pyramidal layers, $\mathrm{Cu}$ atoms are displaced toward the apical oxygen atoms but in the $m=3$ members the copper atoms, located in the median plane, cannot be displaced.

The appearance of defective rock salt-type slabs obeys to different rules. This behaviour can be easily understood if one bears in mind that the existence of multiple rock slabs, $(n>1)$, intergrown with perovskite slabs, is exceptional and observed for the first time the high $T_{\mathrm{c}}$ superconducting cuprates.

"The appearance of defective $n^{\prime}$ rock slabs in a rare phenomenon if the corresponding member, $\left(A C u O_{3-x}\right)_{m}(A O)_{n^{\prime}}$, does not exist as a pure phase".

In the $n=2$ and 3-thallium oxides, complete families have been characterized and the existence of $n^{\prime}=3$ and $n^{\prime}=2$, respectively, defective slabs are frequently observed in the different members (from $m=1$ to $m=4$ ). This perfectly illustrated by the easy formation of polytypes in thallium oxides; an example of $[2,2.66]$ member is shown in figure 3 with a perfect sequence of two triple and one double rock salt slabs intergrown with double perovskite layers. Some $n^{\prime}=1$ [29] and 5 [27-36] defective members have been sometimes observed. However, in the latter case, $n^{\prime}=5$, the high resolution images show that the additional layers are of different composition, suggesting a $[\mathrm{BaO}-\mathrm{TlO}-\mathrm{CaO}-\mathrm{CaO}-\mathrm{TlO}-\mathrm{BaO}]$ sequence in the defective slabs. In the lead oxides, the problem is more complex owing to the mixed character of the $[\mathrm{AO}]_{\infty}$ layers. In the $[2,2]$ members, $\mathrm{Pb}_{0.5} \mathrm{~A}_{0.5} \mathrm{Sr}_{2} \mathrm{Ca}_{0.5} \mathrm{Y}_{0.5} \mathrm{Cu}_{2} \mathrm{O}_{8}$ oxides $(\mathrm{A}=\mathrm{Ca}, \mathrm{Sr})$, intergrowth defects have not been observed. A similar perfect ordering is observed in the bismuth doped oxide [1.5, 1], $\mathrm{Pb}_{1.4} \mathrm{Bi}_{0.6} \mathrm{Sr}_{2} \mathrm{Y}_{0.5} \mathrm{Ca}_{0.5} \mathrm{Cu}_{3} \mathrm{O}_{8}$, (37) but intergrowth defects were reported in the undoped oxides (38-40), the uneven periodicity which was the most often reported is close to $11.9 \AA$ suggesting the presence of the $[2,2]$ phase as defective member.

It should be noted that these intergrowth defects which are easily formed can be controlled in a large part by adequate thermal treatments.

2.1.2 Intercalation of additional layers. - The intercalation of additional layers of different nature is one of the ways to obtain new compounds whose structure is directly related to the "parent structures". One example was observed in the $\mathrm{TlBa}_{2} \mathrm{NdCu}_{2} \mathrm{O}_{7}$ oxide where, besides the classical intergrowth defects, original sequences in the layers stacking were characterized [31]. A HREM image of the defect (Fig. 4a) shows that, at the level of the defect (labelled F) the single [Nd $]_{\infty}$ layer, intercalated between the $\left[\mathrm{CuO}_{2}\right]_{\infty}$ layers, is replaced by a double layer. The shifting of the $\left[\mathrm{CuO}_{2}\right]_{\infty}$ layers resulting from that intercalation, the layers thickness and the contrast led us to 


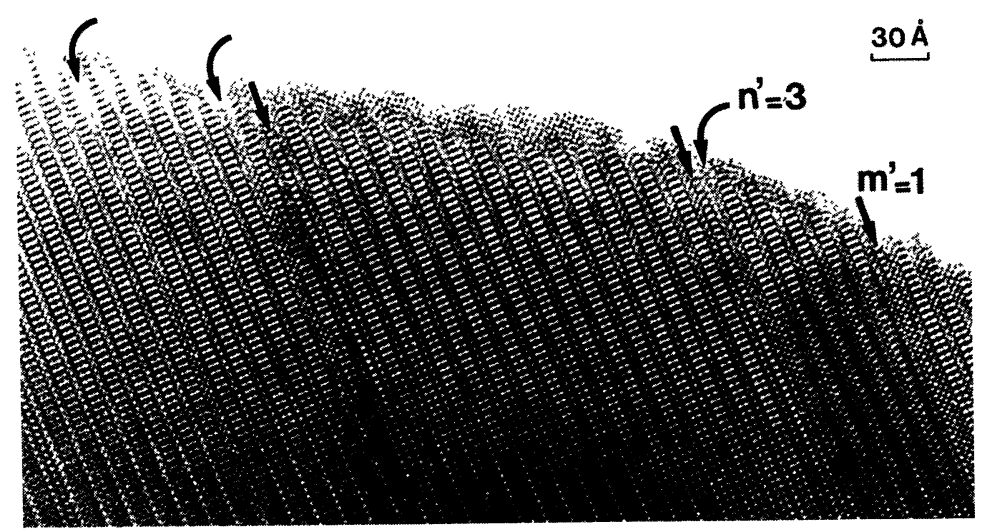

a)
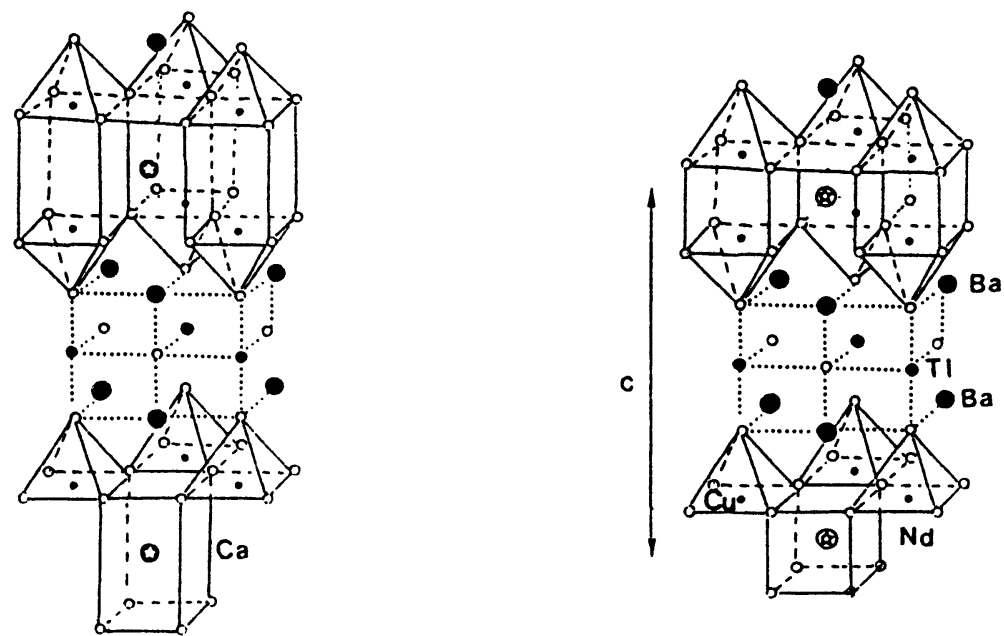

b)

Fig. 2. - a) in $\mathrm{TlBa}_{2} \mathrm{LnCu}_{2} \mathrm{O}_{7}$, [2, 2], only $m^{\prime}=1$ defective perovskite slabs have been observed (straight arrows). b) This feature is correlated with the shape of the $\mathrm{AO}_{8}$ fluorite cage: elongated with $\mathrm{AO}_{8}$ and pseudocubic with Nd and Y.

propose a double fluorite layer $\left[\mathrm{Nd}_{2} \mathrm{O}_{2}\right]_{\infty}$ (Fig. $4 \mathrm{~b}$ ) as new structural unit in the matrix.

The frequent appearance of this double fluorite layer in the form of defect suggested the existence of a new mechanism, confirmed by the synthesis of $\mathrm{TlBa}_{2} \mathrm{Ln}_{2} \mathrm{Cu}_{2} \mathrm{O}_{9}$ phases whose composition and structure are in agreement with the proposed model. Moreover, it opened the road to the synthesis of a new families built up from this principle: every single $[\mathrm{A}]_{\infty}$ layer sandwiched between the two $\left[\mathrm{CuO}_{2}\right]_{\infty}$ layers of a double perovskite slabs can be substituted by a double fluorite layer, $\left[\mathrm{Nd}_{2} \mathrm{O}_{2}\right]_{\infty}$.

The theoretical parameters of the resulting structures can be easily calculated from those of the parent structures, as shown in table II. 


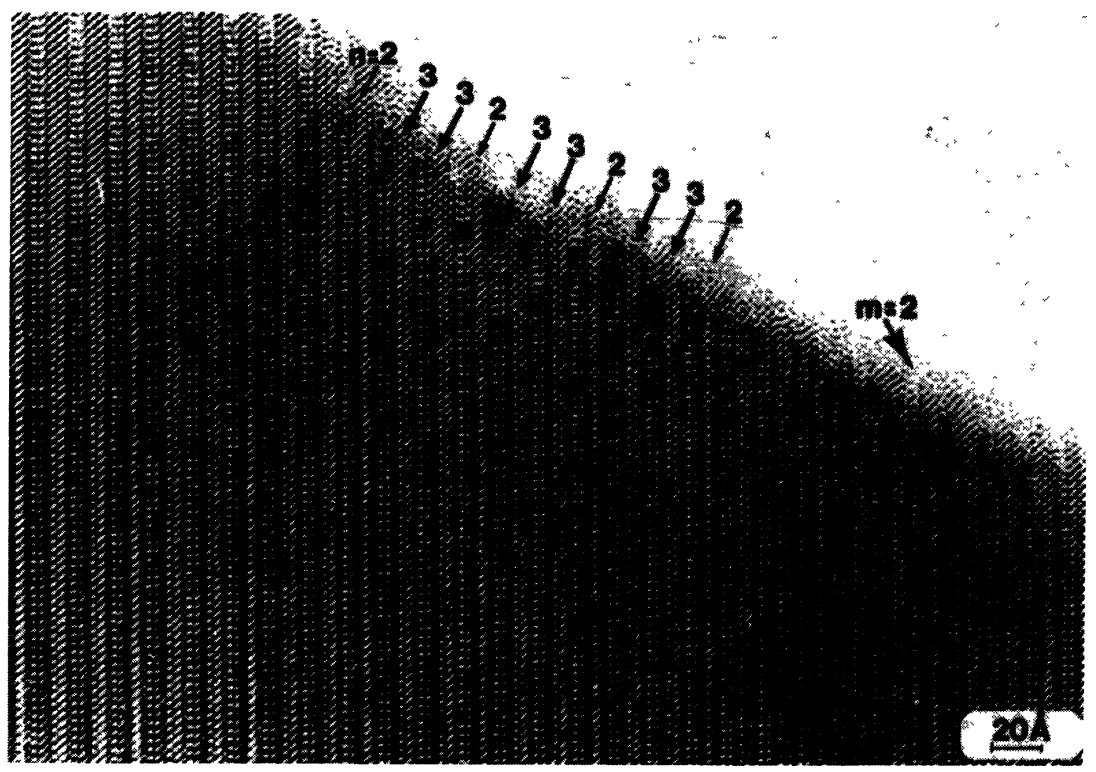

Fig. 3. - $[2,2.66]$ polytype built up from a regular intergowth of one $[2,2]$ member and two $[2,3]$ members.

Table II.

\begin{tabular}{|c|c|c|c|}
\hline \multicolumn{2}{|c|}{ parent structure } & + D.F & related structure \\
\hline $\begin{array}{c}\text { even } \\
n\end{array}$ & $a_{p}, b_{p}$ & & $a_{p}, b_{p}$ \\
values & $c_{n}$ & $\rightarrow$ & $\left(c_{n}+f\right) \times 2$ \\
\hline odd & Space group : P & & SG : I \\
$n$ & $a_{p}, b_{p}$ & & $a_{p}, b_{p}$ \\
values & $c_{n}$ & $\rightarrow$ & $c_{n} / 2+f$ \\
& Space group I & & S.G : P \\
\hline
\end{tabular}

$f=$ thickness of a fluorite layer.

$c_{n}=c$ parameter, calculated from the thickness of the $n$ rock salt layers and $m$ perovskite layers [30].

This new mechansim can be applied not only to the thallium and lead oxides but to every superconducting cuprates exhibiting a $\left[\mathrm{ACuO}_{2.5}\right]_{2}$ unit. It implies, indeed, the adjunction of one $\left[\mathrm{AO}_{2}\right]$ unit per $\left[\mathrm{ACuO}_{2.5}\right]_{2}$ unit which can be ensured by a local variation of stoichiometry in defective slabs but which must be ensured by an appropriate cation balance an the pure phases.

2.2 ORDER-DISORDER PHENOMENA ON THE CATION LATTICE. - A local cationic substitution, as a point defect, cannot be detected in the high resolution images, except on the rrystai edge if 


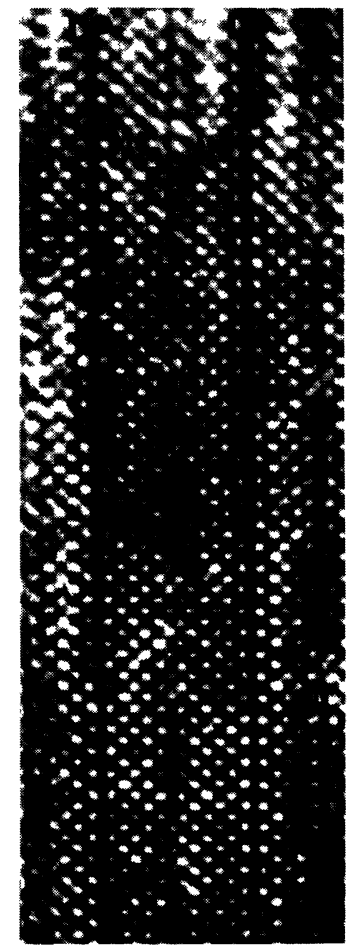

a)

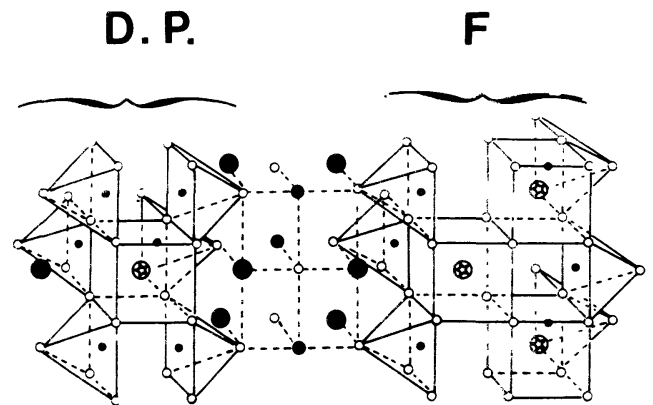

b)

Fig. 4. - a) original defect observed in $\mathrm{TlBa}_{2} \mathrm{NdCu}_{2} \mathrm{O}_{7}$. The double perovskite slabs (DP), built up from $[\mathrm{A}]_{\infty}$ layer intercalated between two pyramidal layers, is replaced by four layers (F). The small arrows indicate the three $[\mathrm{AO}]_{\infty}$ layers of the structure $(n=2)$. b) idealized model of the double fluorite layer, intercalated between the pyramidal $\left[\mathrm{CuO}_{2}\right]_{\infty}$ layers.

it implies a strong disturbance of the neighbouring ions. It is why small deviations from the ideal composition cannot be observed by HREM.

In the simplest system, $\mathrm{Tl}-\mathrm{Ba}-\mathrm{Ca}-\mathrm{Cu}-\mathrm{O}$, the $\mathrm{X}$ ray and neutron diffraction works give evidence of such small deviations on thallium and calcium $\left(\left[\mathrm{Tl}_{2-x} \mathrm{Ca}_{x}\right]_{\mathrm{T}}\right.$ and $\left.\left[\mathrm{Ca}_{1-x} \mathrm{Tl}_{x}\right]_{\mathrm{Ca}}\right)$ with $\left.x \approx 0.1\right)$. The HREM images showed that, locally, thallium ions can substitute a complete row of calcium in the $m=2$ members, involving the existence of a $[\mathrm{Tl}]_{\infty}$ layer intercalated between the two $\left[\mathrm{CuO}_{2}\right]_{\infty}$ planes of the pyramidal layers [27]. However no evidence of such a phenomenon has been observed in the $[\mathrm{TlO}]_{\infty}$ layer and we can thus conclude that the substitution, if it exists, occurs in a statistical way. However, such statistical substitutions sometimes imply structural features which attest, in an indirect way, the substitution is effective. As an example, the Ba-Tl substitution in the 2212 thallium oxide [41] leads to a preferential cieavage of the crystais parallel to the layers and to the systematical appearance of satellites in the electron diffraction patterns, both being very rarely observed in the 2212 oxides. Such phenomena have been correlated with the stereoactivity of the $6 s^{2}$ lone pair of $\mathrm{Tl}^{\mathrm{I}}$, which is assumed to be present in the [BaO] layers owing to its ionic radius.

On the contrary, the lead oxides and the mixed thallium ( $\mathrm{Tl}-\mathrm{Pb}$ and $\mathrm{Tl}-\mathrm{Bi})$ oxides often exhibit the characters of order-disorder phenomena: satellites, local superstructures and modulations [42]. Only two examples are given here:

- frequent superstructure reflections are sbserved in the electron diffraction patterns of the 
mixed $\mathrm{Tl}_{0.5} \mathrm{~Pb}_{0.5} \mathrm{Sr}_{2} \mathrm{CaCu}_{2} \mathrm{O}_{7}$ oxide [42]. A " $a \times 4 a$ " superstructure is shown in figure 5 which can set up along the two equivalent dirctions of the perovskite subcell; the corresponding bright field image shows the $90^{\circ}$ oriented domains. The domain boundaries are mainly parallel to $\langle 110\rangle$ and $\langle 1 \overline{10}\rangle$ and the change in orientation is clearly visible through the $15 \AA\left(4 \times a_{p}\right)$ fringes. Note that a second system of poorly resolved fringes, whose origin is unknown, is superposed to the first ones.

- spectacular cation orderings are locally observed in 1212-type oxide, $\mathrm{Pb}_{0.5} \mathrm{Sr}_{2.5} \mathrm{Y}_{0.5} \mathrm{Ca}_{0.5} \mathrm{Cu}_{2}$ $\mathrm{O}_{7-x}$. On the HREM images (Fig. 6), it appears that they affect the three adjacent $[\mathrm{AO}]_{\infty}$ layers and the through focus series attest that the anionic network is affected too.

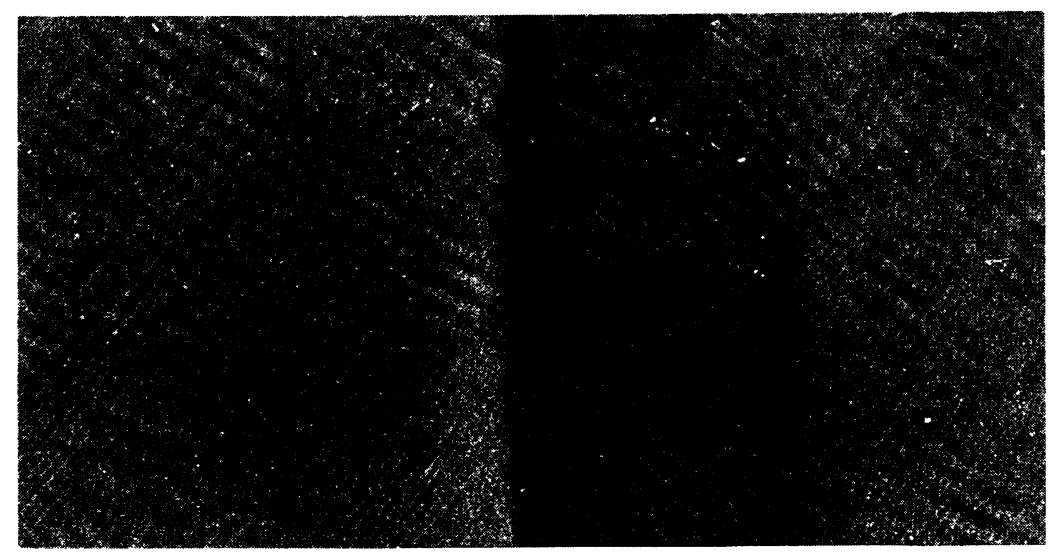

Fig. 5. $-\mathrm{Tl}_{0.5} \mathrm{~Pb}_{0.5} \mathrm{Sr}_{2} \mathrm{CaCu}_{2} \mathrm{O}_{7}: a \times 4 a$ superstructure are observed, which can set up along the two equivalent directions of perovskite cell.

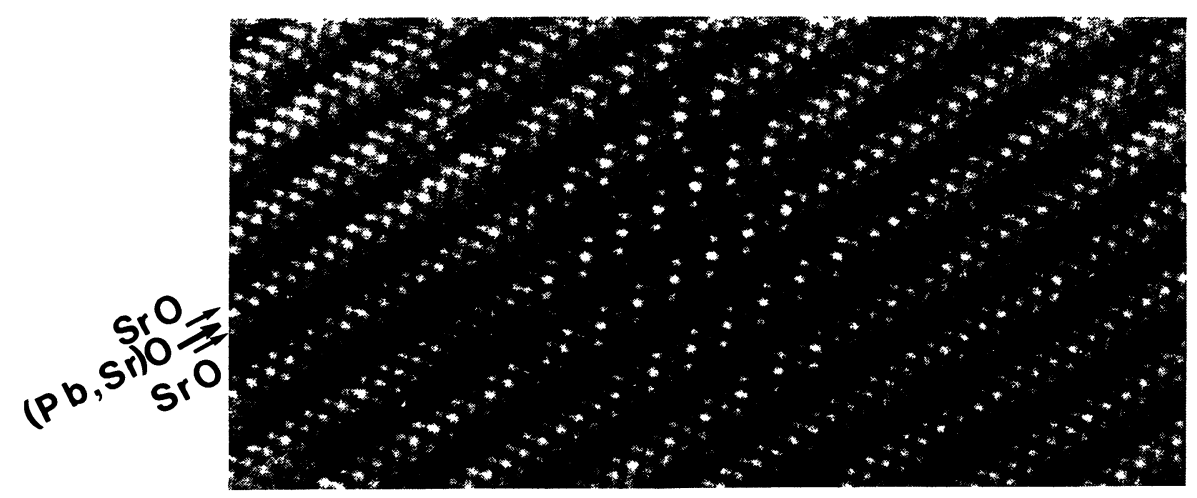

Fig. 6. $-\mathrm{Pb}_{0.5} \mathrm{Sr}_{2.5} \mathrm{Y}_{0.5} \mathrm{Ca}_{0.5} \mathrm{Cu}_{2} \mathrm{O}_{7-x}$ : local cations and anions orderings are observed.

It appears clearly that in the lead and thallium cuprates the order-desorder phenomena are strongly related to the existence of mixed layers; moreover, greater the number of cations in the matrix is, more numerous and complex the domains. 
2.3 Modulations AND SATEllites. - The existence of satellites in incommensurate position appears as the most important characteristic of the bismuth cuprates. Moreover the different substitutions performed in these oxides: $\mathrm{Cu} / \mathrm{Fe}(45-46)-\mathrm{Ca} / \mathrm{Y}-\mathrm{Sr} / \mathrm{Ln}$ and $\mathrm{Bi} / \mathrm{Pb}$ showed that these modulations are directly related with the nature of the double $[\mathrm{BiO}]_{2}$ layers. Nevertheless, although the numerous works devoted to this topic and the interesting hypotheses proposed to explain these phenomena, no certainty can be reached on their origins.

In the lead and thallium oxides, satellites in incommensurate positions have been reported too, but their characteristics are very different from those of bismuth since:

- they are not systematically observed;

- their intensities vary from one crystal to the other in one sample and strongly depend on the thermal treatment;

- they set up along different directions.

In the $\mathrm{Tl}-\mathrm{Ba}-\mathrm{Ca}-\mathrm{Cu}-\mathrm{O}$ system, conflicting results were firstly published on the existence of the satellites; most of the authors [2, 5, 19-20, 30-33] showed satellite-free patterns for the different (members except 2201) whereas others reported the existence of weak satellites setting up along $[100]_{p}^{*}$ which disappear under beam heating [32]. In fact, it was shown that thermal treatments, especially oxygen pressure and real compositions (which can be very different from the nominal compositions according to the synthesis methods) are essential factors for the appearance of the satellites.

In the $\mathrm{PbBiSr}_{2} \mathrm{YCu}_{2} \mathrm{O}_{8}$ oxides, the Bi-type satellites (setting up along [110] $]_{p}^{*}$ with $q \sim 4.7$ ) are no more observed but very complex local superstructures and modulations are sometimes observed [41]. In the 1212-type oxide, $\mathrm{Pb}_{0.5} \mathrm{Sr}_{2.5} \mathrm{Y}_{1-x} \mathrm{Ca}_{x} \mathrm{Cu}_{2} \mathrm{O}_{7}$ [9-11], satellites are observed along [102]* (Fig. 6) whose intensities vary with the $x$ value and the thermal treatment (Fig. 7a). The HREM images show clearly that the origin of this phenomenon is different from those observed in the bismuth oxides. In the latter, the images show indeed that they are correlated with cation displacements in the $\mathrm{SrO}-\mathrm{BiO}-\mathrm{SrO}$ layers whereas in the lead oxides, the images show that they occur at the level of the $\left(\mathrm{ACuO}_{3-x}\right)_{2}$ slab without strong undulations of the layers (Fig. $7 \mathrm{~b}$ ).

The general behaviour of the satellites observed in the thallium and lead cuprates suggests they are mainly related to the oxygen stoichiometry and homogeneity.

2.4 INTERRUPTION OF THE LAYERS. - Several types of defects have been observed which involve the interruption of one or several layers and, sometimes, their connection with an other type of layer.

2.4.1 Dislocations. - In such complex oxides, the term "dislocation" used to point out a type of defect implies to describe the mechanism which originates the phenomenon. In that way, it was shown that in the "123" oxide, the dislocation mechansim corresponds to the intercalation of a segment of additional $\mathrm{CuO}$ layer [43] leading to the formation of a double row of edge sharing $\mathrm{CuO}_{4}$ groups.

In the thallium oxides, the mechanism is very similar i.e. existence of additional rows, but arises at the level of the rock-salt slabs rather than in the perovskite slab [27]. When two or more [CaO $]_{\infty}$ layers are intercalated the $[\mathrm{TlO}]_{\infty}$ layers, they are often interrupted in the matrix and get rise to a "dislocation-like" contrast (Fig. 8).

In the lead oxides, series of dislocations were observed in tilt boundaries, almost parallel to $(010)_{p}$; the junction between the slightly misoriented domains is ensured through shearing mechanisms [37]. 


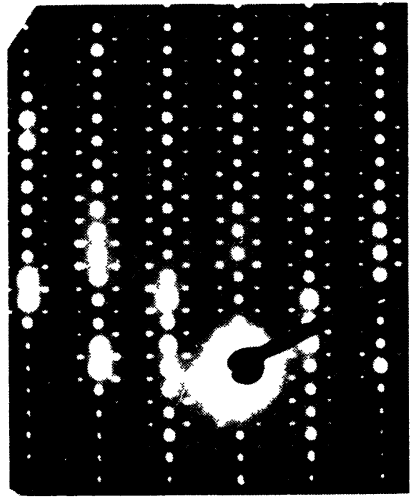

a)

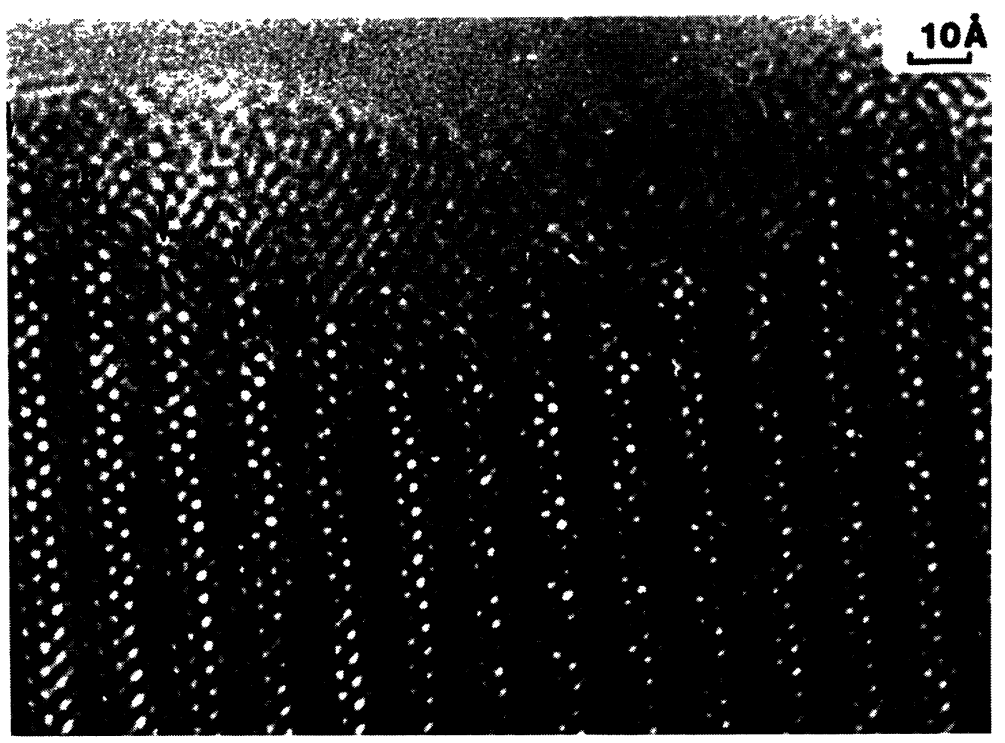

b)

Fig. 7. $-\mathrm{Pb}_{0.5} \mathrm{Sr}_{2.5} \mathrm{Y}_{0.5} \mathrm{Ca}_{0.5} \mathrm{Cu}_{2} \mathrm{O}_{7-x}$ a) [100] electron diffraction pattern, b) the modulations associated with the satellites affect the $\left[\mathrm{Sr}_{2} \mathrm{Y}_{0.5} \mathrm{Ca}_{0.5} \mathrm{Cu}_{2} \mathrm{O}_{5-x}\right]$ perovskite slice.

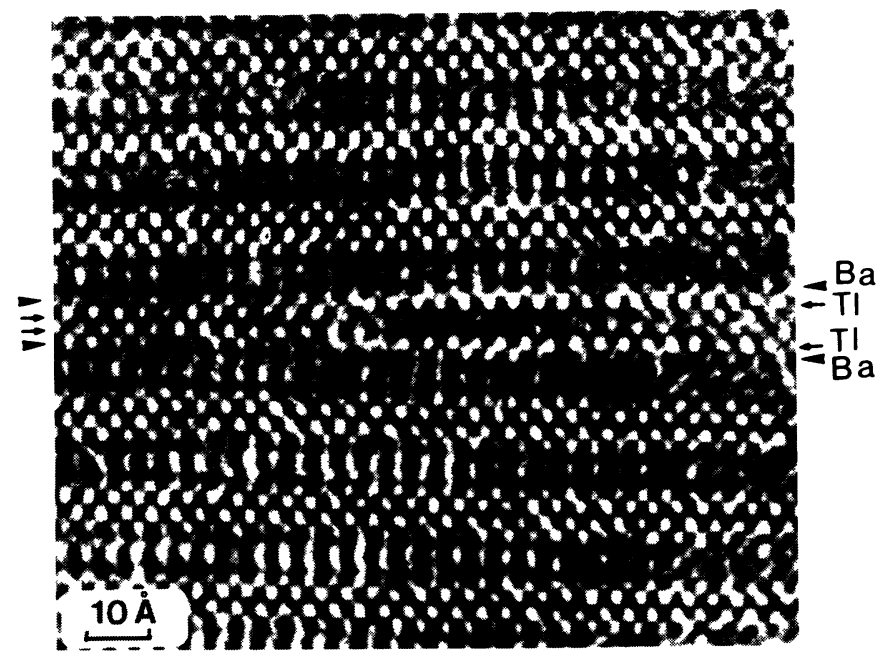

Fig. 8. - Example of "superdislocation" resulting from the interruption of the additional $[\mathrm{CaO}]_{\infty}$ layers in $[2,3]$ thallium oxide.

2.4.2 Antiphase boundaries. - Antiphase boundaries, in these complex oxides, imply the interruption of the layers and their connection with layers of different nature.

Such phenomena have been reported in the lead oxides [37] (and strontium oxides [44]). One image. recorded in $\mathrm{Pb}_{1.4} \mathrm{Bi}_{0.6} \mathrm{Sr}_{2} \mathrm{Ca}_{0.5} \mathrm{Y}_{0.5} \mathrm{Cu}_{3} \mathrm{O}_{8}$, is shown in figures 9a. The boundary is, in that example, parallel to $(101)_{p}$ but other boundaries were found parallel to $(010)_{p}$. A direct corre- 
lation between the images and the nature of the layers allows idealized models to be proposed (Fig. 9b). It appears that, independently of the boundary orientation, some layers remain unchanged through the boundaries but in both cases, $\left[\mathrm{CuO}_{2}\right]_{\infty}$ layers are connected to $[\mathrm{PbO}]_{\infty}$ layers and $\left[\mathrm{Cu}^{+1}\right]_{\infty}$ layers to $\left[\mathrm{AO}_{x}\right]_{\infty}$ layers.
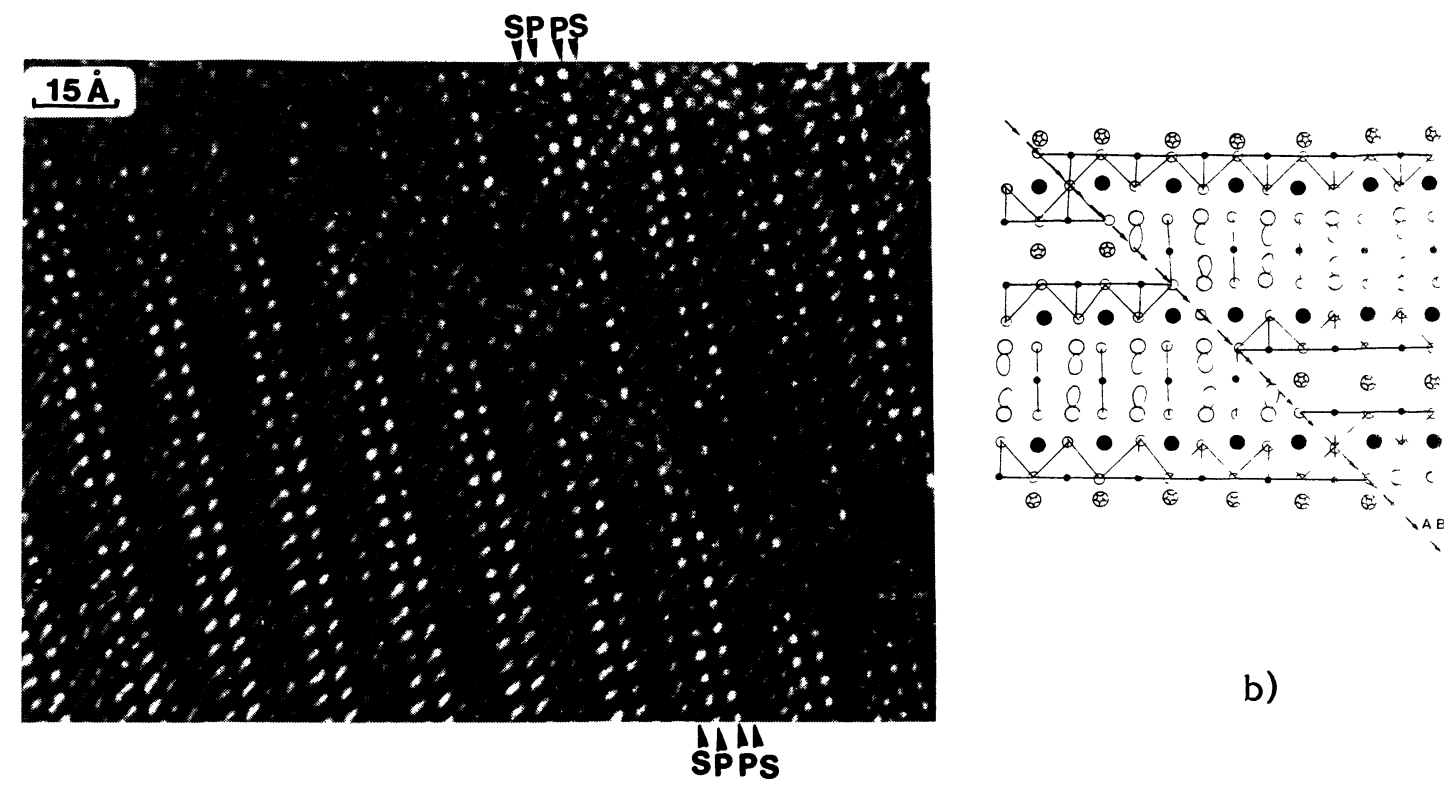

a)

Fig. 9. - a) Image of an antiphase boundary in $\mathrm{Pb}_{1.6} \mathrm{Bi}_{0.4} \mathrm{Sr}_{2} \mathrm{Ca}_{0.5} \mathrm{Y}_{0.5} \mathrm{Cu}_{3} \mathrm{O}_{8}$. The $[\mathrm{PbO}]_{\infty}$ and $[\mathrm{SrO}]_{\infty}$ layers are indicated by $\mathrm{P}$ and $\mathrm{S}$ respectively. $\mathrm{b}$ ) Idealized model of the layer connection through the boundary

From the physical properties point of view, these phenomena lead only to the existence of additional boundaries in the grains but, two interesting points related to the own mechanism must be outlined:

- this mechanism of layer interconnection appears to be general since such features have been observed in neodymium [47] and bismuth cuprates [48];

- this mechanism can lead to local break of the perovskite slabs, whose consequences can be drastic.

2.4.3 Breaks of the perovskite slabs. - In the $\mathrm{Pb}_{1.4} \mathrm{Bi}_{0.6} \mathrm{Sr}_{2} \mathrm{Ca}_{0.5} \mathrm{Y}_{0.5} \mathrm{Cu}_{3} \mathrm{O}_{8}$ oxides, linear defects are observed, extending perpendicularly to the $c$ axis (Fig. 10). The interpretation of the images showed that a mechanism similar to that observed in the antiphase boundaries is responsible of the formation of these defects which can be, in some crystals, numerous. The perovskite slab $\left[\mathrm{SrCaCu}_{2} \mathrm{O}_{5}\right]_{\infty}$ is locally replaced by a $\left[\mathrm{SrCu}^{\mathrm{I}} \mathrm{Pb}_{2} \mathrm{O}_{2}\right]_{\infty}$ slab; the defective segment is some hundred angstroms long (Fig. 10b).

Two features result from this mechanism. Firstly the "superconductive" layers are broken and thus, the physical properties of the samples can be drastically affected. Second, from one hand, copper and lead, and from the other, calcium and monovalent copper appear to be located in the same crystallographic sites; the only difference lies in the positions of the oxygen atoms. This second point can affect the structure refinements. 

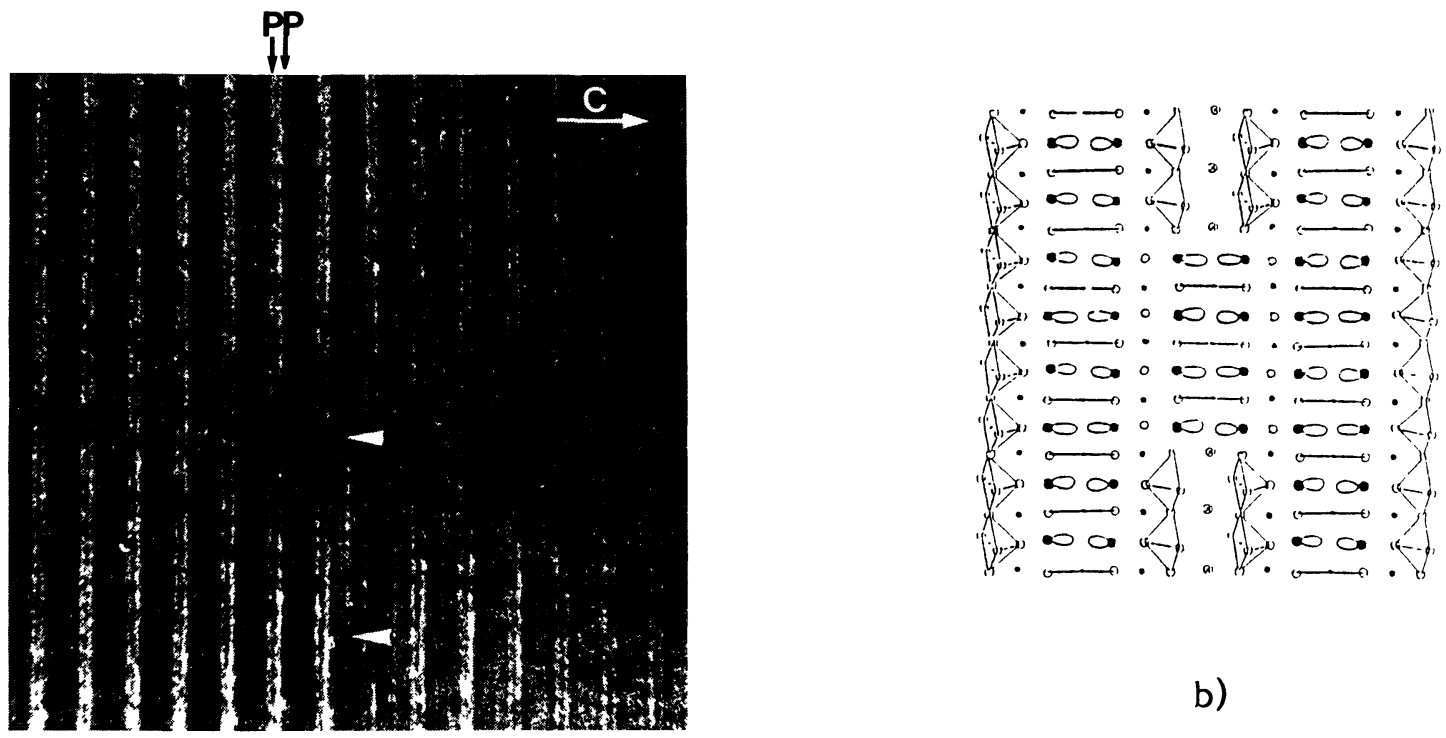

a)

Fig. 10. - a) Image of a linear defect; the white rows are correlated with the $[\mathrm{PbO}]_{\infty}$ layers. b) Idealized model of the defect.

2.5 DOMAINS AND BOUNDARIES. - In the preceding sections some examples of $90^{\circ}$-oriented domains, resulting from the setting up of superstructures and boundaries, (antiphase B and tilt B) have been reported. In fact, such phenomena are considerably rarer than in the 123-type and bismuth oxides owing to tetragonal symmetry of the cells. Only two types of oriented domains are commonly observed in the lead and thallium cuprates:

- small-sized domains resulting from local ion ordering;

- domains resulting from the existence of twist boundary. Those boundaries are quite systematically observed in lead compounds, even in lead poor oxides. Typical electron diffraction patterns are observed with a two-dimensional system of satellites (Fig. 11a); in this classical feature, the satellites arise from double diffraction phenomena resulting from the superposition of two misoriented lamellae. However the constant values of the angle observed between the two components on the E.D. pattern suggest a structural origin for the misorientation. In the same way, in mixed $\mathrm{Bi}_{1.4} \mathrm{~Pb}_{0.6} \mathrm{Sr}_{2} \mathrm{Y}_{0.5} \mathrm{Ca}_{0.5} \mathrm{Cu}_{2} \mathrm{O}_{8}$, the high resolution images (Fig. 11b) show that the typical moire patterns resulting from the superposition of the lamellae is only observed in some crystal areas where modulations set up.

\section{Concluding remarks}

The numerous investigations by high resolution electron microscopy of the layered lead and thallium cuprates have shown the great ability of these oxides to form various extended defects. Thus it is not surprising that the superconducting properties of these materials are so far not optimized if one admits that such defects may affect their electron transport properties. The main issue deals, of course, with the relationships between the presence of these defects and the superconducting properties of the compounds, and especially their influence upon $T_{\mathrm{c}}$ 's. Although it cannot be answered definitely to the different questions, some of them can be partly clarified. 


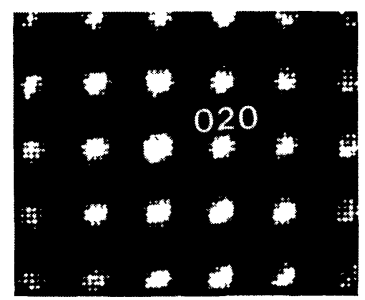

a)

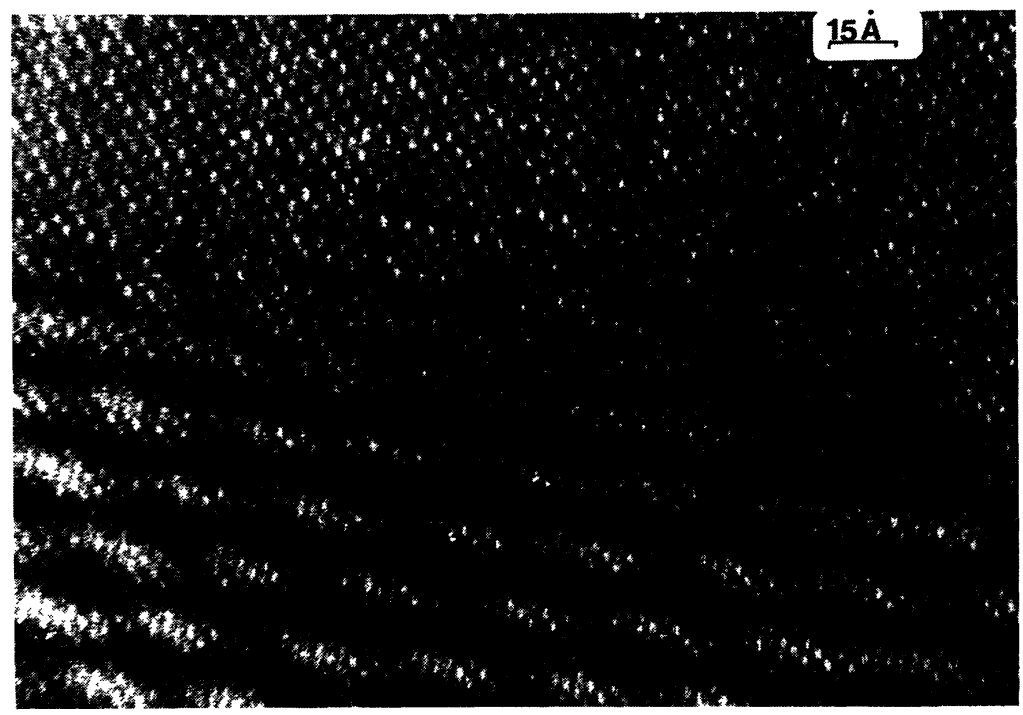

b)

Fig. 11. - a) $\mathrm{Bi}_{1.4} \mathrm{~Pb}_{0.6} \mathrm{Sr}_{2} \mathrm{Y}_{0.5} \mathrm{Ca}_{0.5} \mathrm{Cu}_{2} \mathrm{O}_{8}$ : two dimensional system of satellites observed in a [001] E. D. pattern resulting from the misorientation of the two lamellae. b) Moire are observed in the corresponding images.

The first point, which deals with the influence of intergrowth defects (perovskite or rock salt layers) upon $T_{\mathrm{c}}$ 's, was thought in a first step to be of capital importance. This idea was formulated on the fact that in thallium cuprates $T_{\mathrm{c}}$ 's increases as the number $m$ of copper layers increases for one to three and then decreases again, and that cuprates with thallium bilayers exhibit generally higher $T_{\mathrm{c}}$ 's than those with thallium monolayers. The recent studies of "hydrogen annealing" of thallium cuprates call into question this hypothesis. It was indeed shown [49-50] on perfect materials of $\mathrm{Tl}_{2} \mathrm{Ba}_{2} \mathrm{CuO}_{6+\delta}$ and $\mathrm{Tl}_{2} \mathrm{Ba}_{2} \mathrm{CaCu}_{2} \mathrm{O}_{8+\delta}$, i.e. without intergrowth defects, that the critical temperature can be dramatically increased by annealing under an argon-hydrogen flow at $300{ }^{\circ} \mathrm{C}$ without any destruction of the structure. For instance $T_{\mathrm{c}}$ 's of $\mathrm{Tl}_{2} \mathrm{Ba}_{2} \mathrm{CuO}_{6}(m=1)$ can be increased progressively from $12 \mathrm{~K}$ to $92 \mathrm{~K}$, whereas the critical temperature of $\mathrm{Tl}_{2} \mathrm{Ba}_{2} \mathrm{CaCu}_{2} \mathrm{O}_{8}$ $(m=2)$ can be increased from $96 \mathrm{~K}$ to $118 \mathrm{~K}$, i.e. close to that obtained for the $m=3$-phase $\mathrm{Tl}_{2} \mathrm{Ba}_{2} \mathrm{Ca}_{2} \mathrm{Cu}_{3} \mathrm{O}_{10}$ which exhibits the highest $T_{\mathrm{c}}$ 's $(125 \mathrm{~K})$. Thus, it appears that the number $m$ of copper layers is not so important for $T_{\mathrm{c}}$ 's as believed in a first step and that the number of hole carriers, i.e. the very small deviation from oxygen stoichiometry, plays a predominant role. Consequently the appearance of such intergrowth defects should not affect drastically the critical temperature of the thallium cuprates.

On the opposite, the "intercalation" of additional $[\mathrm{AO}]_{\infty}$ layers between copper slabs, leading to double fluorite-type layers should tend to kill the superconducting properties as shown from the investigations performed on oxides involving double fluorite type layers which are either non superconducting or exhibit $T_{\mathrm{c}}$ 's smaller than $60 \mathrm{~K}$ [24-25, 51-52]. In the same way, the introduction of additional $[\mathrm{CaO}]_{\infty}$ layers, leading to "superdislocations", which increases the thickness of the "normal" layers should tend to weaken the superconducting properties in agreement with the arguments based on the proximity effect developped by Tournier et al. [53].

There is no doubt that the formation of domains involving the breaking of $\left[\mathrm{CuO}_{2}\right]_{\infty}$ layers is nefast for superconductivity since it hinders the propagation of holes in the structure. In a more general way, all the desorder phenomena, either on the cationic sublattice or on the oxygen 
sublattice, leading to inhomogeneity of the materials must be taken into consideration since thay can affect drastically the superconducting properties.

The origin of incommensurate satellites is not really known up to now in those oxides, so that it is difficult to establish their relationships with superconductivity. Nevertheless, if it is true that they are due to oxygen non stoichiometry and inhomogeneity, there should appear correlations between the modulation of the structure and the superconducting properties of these materials.

In any case, the understanding of the superconducting properties of the layered cuprates passes through the knowledge of their microstructure, and in this respect, high resolution electron microscopy remains a privileged tool for their investigation, provided such observations can be connected with the superconducting properties of the samples.

\section{References}

[1] Raveau B., Michel C. and Hervieu M., Princeton Congress, june 1988, Solid State Ionics 32 (1989) 1035.

[2] Hervieu M., Maignan A., Martin C., Michel C., Provost J. and RAVEAU B., J. Solid State Chem. 75 (1988) 212.

[3] Rouillon T., Retoux R., Groult D., Michel C., Hervieu M., Provost J. and Raveau B., J. Solid State Chem. 72 (1989) 322.

[4] Martin C., Bourgault D., Michel C., Provost J., Hervieu M. and Raveau B., E. J. I SSC 26 (1989) 1.

[5] Bourgault D., Martin C., Michel C., Hervieu M., Provost J. and Raveau B., J. Solid State Chem. 72 (1989) 326.

[6 Martin C., Bourgault D., Michel C., Hervieu M., Raveau B., Mod. Phys. Lett. B 3 (1989) 93.

[7] Hervieu M., Domenges B. and RaVeau B., J. Microsc. Spectrosc. Electron. 13 (1988) 279.

[8] Subramanian M. A., Torardi C. C., Gopalakrishnan J., GAi P. L., Calabrese J. C., Askew T. R., FLIPPEN R. B. and SLEIGHT A. W., Science 242 (1988) 209.

[9] Rouillon T., Provost J., Hervieu M., Groult D., Michel C. and Raveau B., Physica C 159 (1989) 201.

[10] Rouillon T., Provost J., Hervieu M., Groult D., Michel C. and Raveau B., J. Solid State Chem. 84 (1990) 375.

[11] Rouillon T., Maignan A., Hervieu M., Michel C., Groult D. and Raveau B., Physcia C 171 (1990) 7.

[12] Li S. and GREENBlatT M., Physica C 157 (1989) 365.

[13] Martin C., Michel C., Maignan A., Hervieu M. and Raveau B., C.R. Ac. Sci. April 11307 (1988) 27.

[14] Sugise R., Hirabayashi H., Terada N., Jo M., Shimomura T. and Ihara H. Physica C. 157 (1989) 131.

[15] Torardi C. C., Subramanian M. A., Calabrese J. C., Gopalakrishnan J., Mc Carron, Morissey K. J., ASKew T. R., FlipPen R. B., ChOWDhry U. and Sleight A. W., Phys. Rev. B 38 (1988) 225.

[16] HaZen R. M., Finger D. W., ANGel R. J., PREvitT C. T., ROSS N. L., Hadidiacos C. G., Heaney P. J., Veblen R. D., Sheng Z. Z., El Ali A. and Hermann A. M., Phys. Rev. Lett. 60 (1988) 1657.

[17] Retoux R., Caignaert V., Provost J., Michel C., Hervieu M. and Raveau B., J. Solid State Chem. 79 (1989) 157.

[18] Bourgault D., Martin C., Michel C., Hervieu M. and Raveau B., Physica C 158 (1989) 511.

[19] Torardi C. C., Subramanian M. A., Calabrese J. C., Gopalakrishnan J., Morissey K. J., ASkew T. R., FlipPEn R. B., ChOWDHRY U. and Sleight A. W., Science 240 (1988) 631.

[20] Hervieu M., Maignan A., Martin C., Michel C., Provost J. and Raveau B., Modern Phys. Lett. 2 (1988) 1103.

[21] CAVA R. J., BATlogg B., KRAJecosky J. J., RuPP L. W., SChNEEMEYeR L. F., SiegRist T., VAN DoveR R. B., Marsh P., Peck W. F., Gallagher P. K., Glarum S. H., Marshall J. H., Farrow R. C., WASZCZAK J. V., HULl R. and TREVOR P., Nature 336 (1988) 211.

[22] Retoux R., Michel C., Hervieu M. and Raveau B., Mod. Phys. Lett. B 3 (1989) 591. 
[23] Zandbergen H. W., Fu W. T., Ruitenbeek J. M., De Jongh L. J., VAN Tendeloo G. and AmelinckX S., Physica C. 159 (1989) 81.

[24] Martin C., Bourgault D., Hervieu M., Michel C., Provost J. and Raveau B., Mod. Phys. Lett. B. 3 (1989) 93.

[25] Rouillon T., Groult D., Hervieu M., Michel C. and Raveau B., Physica C. 167 (1990) 107.

[26] Martin C., Bourgault D., Hervieu M., Provost J., Michel C. and Raveau B., Mod. Phys. Lett. $B 3$ (1989) 1143.

[27] Hervieu M., Martin C., Provost J. and Raveau B., J. Solid State Chem. 76 (1988) 419.

[28] Domenges B., HeRvieu M. and RAVEAU B., Solid State Commun. 68 (1988) 303.

[29] Domenges B., Hervieu M. and Raveau B., Solid State Commun. 69 (1989) 1085.

[30] HeRVIEU M., DOMENGeS B. and RAVEAU B., J. Microsc. Spectrosc. Electron. 13 (1988) 279.

[31] Domenges B., Hervieu M., Martin C., Bourgault D., Michel C. and Raveau B., Phase transitions $B 19$ (1989) 231.

[32] Zandbergen H. W., Van Tendeloo G., Van landuyt J. and Amelinckx S., Appl. Phys. $A 46$ (1988) 233.

[33] Zhang J. P., Li D. J., ShibahaRa H. and MaRks L. D., Supercond. Sci. Technol 1 (1988) 132.

[34] Verwerft M., VAN Tendeloo G. and AMElinckx S., Physica C 156 (1988) 609.

[35] IIJIMA S., ICHIHASHI T., ShIMAKAWA Y., MANAKO T. and KUBO Y., Jpn J. Appl. Phys. 27 (1988) L 1054.

[36] Maignan A., Michel C., Hervieu M., Martin C., Groult D. and Raveau B., Mod. Phys. Lett. B. 2 (1988) 681.

[37] Hervieu M., Caignaert V., Retoux R. and Raveau B., Mat. Sci. Eng. B 6 (1990).

38 GoOdMAN P., JeNSEN D. G. and WhITE J. J., Physica C 158 (1989) 173.

(39] Hull R., Bonar J. M., SCheEMEYer L. F., CAVA R. J., KRAJEwSKi J. J. and WASZCZAK J. V., Phys. Rev. $N 39$ (1989) 9685.

[40] Zandbergen H. W., Kadokawi K., Menken M. J. V., Menovsky A. A., Van Tendeloo G. and AMELINCKX S., Physica C 158 (1989) 155.

[41] Bourgault D., Martin C., Michel C., Hervieu C. and Raveau B., Physica C 158 (1989) 511.

[42] Martin C., Provost J., Bourgault D., Domenges B., Michel C., Hervieu M. and Raveau B. Physica C. 157 (1989) 460.

[43] Domenges B., Hervieu M., Michel C. and RaVEau B., Europhys. Lett. 4 (2) 1987.

[44] Hervieu M., Caignaert V., Michel C., Retoux R. and RaVEaU B., M. M. Microstr. 1 (1990) 109.

[45] HeRvieu M., Michel C., NGUYen N., RetouX R. and RAVEAU B., European J. Solid State Ionorg. Chem. 25 (1988) 375.

[46] Retoux R., Michel C., Hervieu M., NguYen N. and Raveau B., Solid State Commun. 69 (1989) 599.

[47] HeRvieu M., CAIGNAERT V., Michel C., Retoux R. and RAVEAU B., Microsc. Microanal Microstruct. 1 (1990) 109.

[48] Eibl O., Physica C 168 (1990) 239-249.

[49] Maignan A., Martin C., Huve M., Provost J., Hervieu M., Michel C. and Raveau B., Physica $C$ 170 (1990) 350.

[50] Martin C., Maignan A., Provost J., Michel C., Hervieu M., Tournier R. and Raveau B., Physica $C 168$ (1990) 8.

[51] Sawa H., Obara K., Akimitsu J., MatSui Y., Oriushi Y., J. Phys. Soc. Jpn 58 (1989) 2252.

[52] Tokura Y., Arima T., TaKagi H., Ushida S., Ishigaki T., ASANo H., Beyers R., NazZal A. I., JENSEN D. G. and WhITE J. J., Physica C 158 (1989) 173.

[53] De Rango P., Giordanengo B., TOURnier R., Sulpice A., Chaussy J., Deutscher G., Genicon J. L., LeJay P., RetouX R. and RaVeau B., J. Phys. France 50 (1989) 2857. 